\title{
OCORRÊNCIA DO CANCRO DE TRONCO EM ÁRVORES DE ACOMPANHAMENTO VIÁRIO NA CIDADE DE MARINGÁ, PARANÁ
}

Bruno Luiz Domingos De Angelis ${ }^{1}$, Rosana Miranda de Castro ${ }^{2}$, Generoso De Angelis Neto ${ }^{3}$.

\section{RESUMO}

O presente trabalho foi realizado na Cidade de Maringá, Paraná, em duas áreas distintas Zona 1 e Zona 2. A Zona 1 representa a área mais central da cidade, caracterizada por intenso movimento de pessoas e automóveis, enquanto a Zona 2 caracteriza-se por ser uma área residencial de menor trânsito. Como primeira etapa do trabalho realizou-se o censo total da arborização encontrada nas duas áreas, identificando-se os indivíduos e cadastrando-os. Em uma segunda etapa identificou-se as árvores que apresentavam manifestação da doença. Das árvores com manifestação do cancro colheram-se os seguintes dados: DAP, altura, diâmetro da copa, área livre de permeabilização, comportamento do sistema radicular, área do cancro e situação de poda da parte aérea. Estabeleceu-se 5 graus de severidade com relação à área total da doença. Foram reconhecidos no campo sintomas da doença que se manifestam ocupando área do tronco que vai desde $4 \mathrm{~cm}^{2}$ a $20.000 \mathrm{~cm}^{2}$. De um total de 4.446 árvores distribuídas em 34 diferentes espécies, os dados mostram que 17,31 \% das árvores da Zona 1 apresentam manifestação do cancro, enquanto na Zona 2 essa freqüência é da ordem de 11,88 \%. A princípio tem-se que esta diferença possa ser creditada ao fato da Zona 1 estar localizada na região central da cidade onde as situações de estresse são maiores.

Palavras-chave: vegetação urbana, patologia em árvores, arborização urbana.

1. Engenheiro Agrônomo, Professor, Universidade Estadual de Maringá, Maringá, Paraná, bldangelis@uem.br.

${ }_{2}^{2}$ Engenheira Agrônoma, Mestre em Agronomia.

${ }^{3}$. Engenheiro Civil, Professor, Universidade Estadual de Maringá, Maringá, Paraná, ganeto@uem.br. 


\title{
OCCURRENCE OF THE CANCER OF TRUNK IN TREES OF ROAD ACCOMPANIMENT IN THE CITY OF MARINGÁ, PARANÁ
}

\begin{abstract}
The present work was carried through in the City of Maringá, Paraná, in two distinct areas Zona 1 and Zona 2. Zona 1 represents the area most central of the city, characterized for intense movement of people and automobiles, while Zona 2 is characterized for being a residential area of lesser transit. As first stage of the work became fullfilled the total census of the arborization found in the two areas, identifying itself the individuals and registering in cadastre them. In one second stage one identified the trees that presented manifestation of the illness. Of the trees with manifestation of the cancer the following data had been harvested: DAP, height, diameter of the pantry, free area of permeabilization, behavior of the root system, area of the cancer and situation of pruning of the aerial part. One established 5 degrees of severity with regard to the total area of the illness. They had been recognized in the field symptoms of the illness that if reveal occupying area of the trunk that goes since 4 $\mathrm{cm}^{2}$ the $20,000 \mathrm{~cm}^{2}$. Of a total of 4.446 trees distributed in 34 different species, the data show that $17.31 \%$ of the trees of Zona 1 present manifestation of the cancer, while in Zona 2 this frequency is of the $11,88 \%$ order. The principle is had that this difference can be credited to the fact of Zona 1 to be located in the central region of the city where the situations of stress is bigger.
\end{abstract}

Key words: urban vegetation, pathology in trees, urban arborization. 


\section{INTRODUÇÃO}

A cidade de Maringá, com população estimada de 320 mil habitantes, é citada no cenário nacional como referência pela qualidade de vida, e isso decorre, principalmente, em função da existência dos espaços verdes. Fundada em 10 de maio de 1947, seu crescimento é baseado em um plano de desenvolvimento urbano, tendo a frente à Companhia Melhoramentos Norte do Paraná - CMNP. O projeto da cidade foi responsabilidade do arquiteto e urbanista Jorge de Macedo Vieira. O arquiteto criou um arrojado e moderno projeto com avenidas largas e muitas praças, tudo isso seguindo as recomendações da CMNP (PMM, 2004).

Segundo trabalho desenvolvido por Sampaio e De Angelis (2006), Maringá apresenta plantada ao longo de suas vias cerca de 95 mil árvores distribuídas em 113 diferentes espécies. Desse universo, o somatório das freqüências das dez primeiras espécies corresponde a 74,76\% da população ${ }^{4}$. Quanto à qualidade das árvores analisadas, concluiuse que 18,23\% encontram-se em condição geral boa, 49,24\% em condição geral satisfatória e 35,52\% apresentam-se em condição geral sofrível. No tocante ao índice de área verde per capita, o trabalho mostra que é da ordem de 25,24 $\mathrm{m}^{2}$.

De acordo com Milano (1988), a cidade de Maringá, considerada modelo de arborização no Brasil, apresenta-se como laboratório perfeito para as pesquisas necessárias ao desenvolvimento do processo no setor. Segundo Meneghel (2001), Maringá vista de cima parece uma cidade perdida na floresta, os prédios emergem da massa verde composta por árvores plantadas em ruas e praças.

Os problemas relacionados com a arborização de acompanhamento viário em Maringá são os mais diversos: idade avançada em que parte considerável das árvores se encontra; podas irregulares com falta de conhecimento técnico, o que facilita a incidência de patógenos; infestação de certas pragas, como os cupins e as formigas; e ocorrência de doenças, como o cancro de tronco. Sampaio e De Angelis (2006), constataram que 13,72\% da arborização viária de Maringá apresentam-se atacada por cupins. De acordo com Bernatzky (1980) não são pequenas as dificuldades enfrentadas no revestimento verde das cidades. Ainda segundo o autor vários elementos, por vezes antagônicos devem ser conciliados, não é fácil harmonizar, no exíguo espaço das vias públicas, a presença dos equipamentos urbanos como instalações elétricas, telefônicas ou sanitárias com a implantação do verde.

\footnotetext{
${ }^{4}$ Sibipiruna responde por $39,21 \%$, ipê-roxo por $10,28 \%$, tipuana por $6,72 \%$, oiti por $3,49 \%$, falsa-murta por $3,18 \%$, jacarandá por $2,87 \%$, ligustro por $2,78 \%$, alecrim por $2,74 \%$, ipê-amarelo por $1,98 \%$ e flamboyant por $1,50 \%$.
} 
O cancro do tronco é um dos problemas mais notável encontrado hoje na arborização de Maringá. Nota-se que esta doença ataca árvores de todas as idades, no entanto, o processo de necrose encontra-se mais desenvolvido em árvores mais velhas. $A$ doença inicia-se pela entrada do patógeno por algum ferimento, via de regra causado pelo homem, podendo ser resultante de poda, desbrota, ou então danos causados por insetos, brocas, etc.

Constata-se que a área central de Maringá possui um visível maior número de árvores com sintomas do cancro, fato que deixa claro a influência do homem como agente causador dessa patologia. Outros fatores como a poluição, o estresse da árvore, que muitas vezes não possui área livre de permeabilização, também devem ser levados em consideração, já que são fatos de maior ocorrência na área central. As grandes edificações exigem uma poda mais severa, o trânsito de pessoas exige área livre de permeabilização menor, enfim, a realidade da arborização em uma área central e uma área residencial são bem diferentes.

O presente trabalho consiste na realização de um censo total da arborização de duas áreas distintas da cidade, Zona 1 - região central - e Zona 2, representando uma área residencial da cidade. A escolha destas duas áreas se deve ao fato de serem áreas distintas, sendo a Zona 1 uma área poluída com transito intenso de carros e pessoas, e a Zona 2 um bairro residencial e relativamente tranqüilo. No entanto, são também áreas com características em comum, por estarem próximas, terem a mesma composição arbórea e idade de implantação da arborização. Neste censo foram levantadas as espécies e quais ocorrem com maior freqüência. Já em uma segunda etapa foi realizado o censo total da arborização que se encontra com a doença, onde no caso destas árvores foram levantados os seguintes dados: DAP, altura da árvore, diâmetro de copa, área livre de permeabilização, área ocupada pelo cancro e situação do sistema radicular. Levantaram-se também as espécies com maior ocorrência de cancro. Não há nenhum estudo ou dados qualiquantitativos que abordem a presente temática em Maringá. Porém, é notório e perceptível que diversas espécies arbóreas têm sofrido a ação patogênica. A pesquisa propiciará embasamento ao poder público em suas ações de planejamento da arborização de Maringá, no sentido de se ter um parâmetro a mais quando da escolha das espécies.

\section{Ocorrência do cancro em espécies arbóreas}

O cancro é um sintoma caracterizado por lesões necróticas, deprimidas, mais freqüentes nos tecidos corticais de caules, raízes e tubérculos. Eventualmente, este tipo de sintoma é observado em folhas e frutos (Salgado e Amorim, 1995).

A ocorrência do cancro em espécies de arborização urbana em nosso país não é relatada em literatura. Os relatos de cancro mais comumente referenciados são os 
ocorrentes em espécies com valor comercial para madeira, celulose ou outros fins. $O$ eucalipto é uma das espécies mais referenciadas na literatura, seguido da seringueira e espécies pertencentes ao gênero Pinus.

Com relação ao agente causal do cancro em espécies arbóreas tem-se a presença sempre de um fungo. Junior (2001) relata que o cancro do eucalipto é uma das doenças mais importantes de ocorrência no campo e é causado por várias espécies de fungos como Cryphonectria cubensis, Valsa ceratosperma (fase sexuada), Cytospora spp (fase assexuada) e Botryosphaeria ribis. Segundo Valente (2001) o cancro do eucalipto é definido por uma lesão ladeada por calos, que mata o câmbio de parte do tronco. Santos et al. (2001) também relatando cancro em eucalipto, diz que o sintoma aparece inicialmente na forma de uma depressão da casca e do câmbio, quando do desenvolvimento da lesão se verifica a formação de um tecido caloso em torno desta.

De acordo com Santos et al. (2001), a morte ou tombamento pelo vento de árvores atacadas chega a ocorrer em proporções elevadas em áreas plantadas com espécies mais susceptíveis. Essa constatação explica, em parte, o grande número de árvores que caem em Maringá, cerca de 30, por ocasião de ventos e chuvas mais fortes. Essas quedas ocorrem, sobretudo, na região central da cidade, justamente onde as características locais submetem as árvores a uma situação de estresse mais acentuado, concorrendo para uma maior incidência do cancro de tronco.

\section{MATERIAIS E MÉTODOS}

\section{Caracterização da área de estudo}

O presente trabalho foi realizado na cidade de Maringá em duas áreas distintas: Zona 1 e Zona 2. A Zona 1 representa a área mais central de Maringá, caracterizando-se por: local de tráfego intenso; considerado poluído pelas descargas dos escapes dos automóveis; apresenta restrita área livre na base das árvores para absorção das águas pluviais; "competição" intensa das árvores com as infra-estruturas aéreas (fiação elétrica de alta e baixa tensão, cabos telefônicos e de TV a cabo), subterrâneas (redes de esgoto e água tratada, galerias pluviais e cabos de telefonia) e de superfície (posteamento, lixeiras, guarda-bicicleta, placas de sinalização, protetores de árvores,...), além das edificações de grande porte. Por sua vez a Zona 2 é classificada pela lei de zoneamento do município como sendo residencial, caracterizando-se por local de trânsito veicular menos intenso; menor índice de poluição; maior ocorrência de área livre na base das árvores; menor "competição" das espécies arbóreas com as infra-estruturas, além de ser possível constatar um maior cuidado dos moradores da região com a árvore fronteiriça ao seu lote (ou residência). 
As duas áreas foram escolhidas tendo em vista que se pretende um estudo comparativo entre os fatores que determinam, ou exacerbam, o cancro na arborização de acompanhamento viário, a partir de situações de estresse para as árvores. Dessa forma, a Zona 1 representa uma área com características particulares que submetem as árvores a situação desejada, enquanto a Zona 2 seria o contraponto a essa situação.

\section{Levantamento da arborização}

Como primeira etapa do trabalho foi realizado o censo total da arborização encontrada nas duas áreas. Este levantamento ocorreu nos meses de março a junho de 2005, ocasião na qual se levantou a população total de árvores no local, bem como a sua espécie. $O$ censo foi realizado com a contagem das árvores uma a uma, onde as mesmas foram identificadas por uma codificação alfa-numérica, sendo que a letra representa a via pública e o número a árvore levantada. Concluído o levantamento quantitativo e de identificação dos indivíduos deu-se início à segunda etapa do levantamento de campo.

\section{Caracterização dos indivíduos arbóreos com manifestação do cancro}

Após o levantamento quantitativo foi possível a realização da segunda etapa do trabalho, onde se identificou as árvores que apresentavam manifestação da doença. Das árvores com manifestação do cancro colheram-se outras informações, conforme apresentado: DAP, altura da árvore, diâmetro da copa, área livre de permeabilização, situação do sistema radicular (classificou-se o sistema radicular em um dos três tipos apresentados: (a) sem afloramento das raízes, (b) com afloramento das raízes na área livre, e (c) raízes causando danos ao calçamento), área do cancro (foi medida com auxílio de uma trena, comprimento versus largura, obtendo-se sua área em centímetros quadrados), poda da parte aérea (foi classificada como poda drástica ou não).

\section{Grau de severidade da doença}

De acordo com Amorim (1995), na quantificação de severidade a porcentagem da área de tecido coberto por sintomas retrata melhor a intensidade da doença. Horsfall e Cowling (1978), apud Amorim (1995), utilizaram para avaliação da ferrugem do trigo cinco seções de folhas com 1, 5, 10, 20 e 50\% de área foliar atacada. Estas escalas são freqüentemente utilizadas para avaliação de doenças. Outros autores utilizam notas que representam quantidade de plantas com sintoma no campo.

Para poder trabalhar melhor os dados levantados em relação à área total da doença estabeleceu-se 5 graus de severidade. Foram reconhecidos no campo sintomas da doença que se manifestam ocupando área do tronco que vai desde $4 \mathrm{~cm}^{2}$, o que equivale a 0,0004 $\mathrm{m}^{2}$, a $20.000 \mathrm{~cm}^{2}$, equivalendo a $2 \mathrm{~m}^{2}$. 
A partir dos dados colhidos estabeleceu-se a árvore padrão como sendo aquela com maior área ocupada pelo cancro. Tendo este dado foi possível visualizar que uma árvore com $20.000 \mathrm{~cm}^{2}-2 \mathrm{~m}^{2}$ - de cancro em seu tronco, é uma árvore com grau de severidade elevadíssimo. Estabeleceu-se que uma árvore com 50\% do tronco atacado também deve ser considerada uma árvore com severidade muito alta da doença. A partir desse parâmetro estabeleceram-se os demais, conforme segue:

$\checkmark$ Grau 1 - Severidade muito baixa - até $1 \%$ ou $200 \mathrm{~cm}^{2}$ do tronco com sintoma (Figura $1)$;

$\checkmark$ Grau 2 - Severidade baixa - de $1 \%$ ou $201 \mathrm{~cm}^{2}$ a $5 \%$ ou $1.000 \mathrm{~cm}^{2}$ do tronco com sintoma (Figura 2);

$\checkmark$ Grau 3 - Severidade média - de $5 \%$ ou $1.001 \mathrm{~cm}^{2}$ a $25 \%$ ou $5.000 \mathrm{~cm}^{2}$ do tronco com sintoma (Figura 3);

$\checkmark$ Grau 4 - Severidade alta - de $25 \%$ ou $5.001 \mathrm{~cm}^{2}$ a $50 \%$ ou $10.000 \mathrm{~cm}^{2}$ do tronco com sintoma (Figura 4);

$\checkmark$ Grau 5 - Severidade muito alta - mais de $50 \%$ ou $10.001 \mathrm{~cm}^{2}$ do tronco com sintoma de cancro (Figura 5).

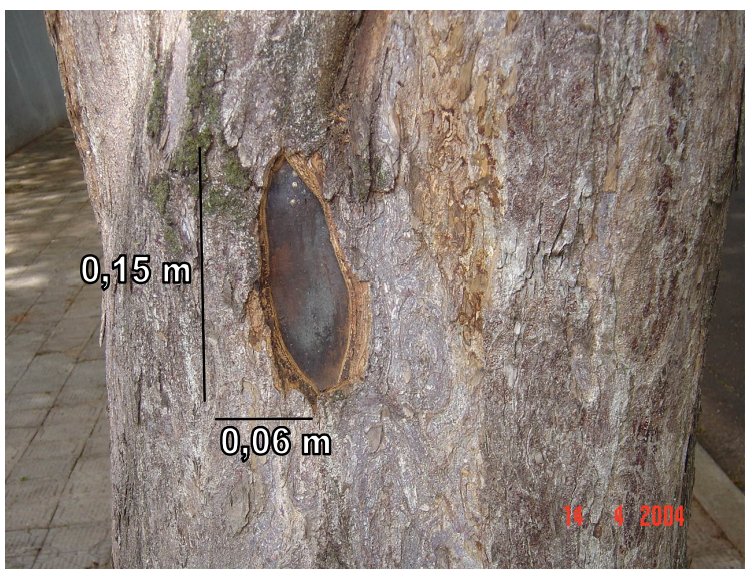

Figura 1 - Manifestação de cancro em Caesalpinea peltophoroides (sibipiruna), com grau de severidade 1 - severidade muito baixa. 


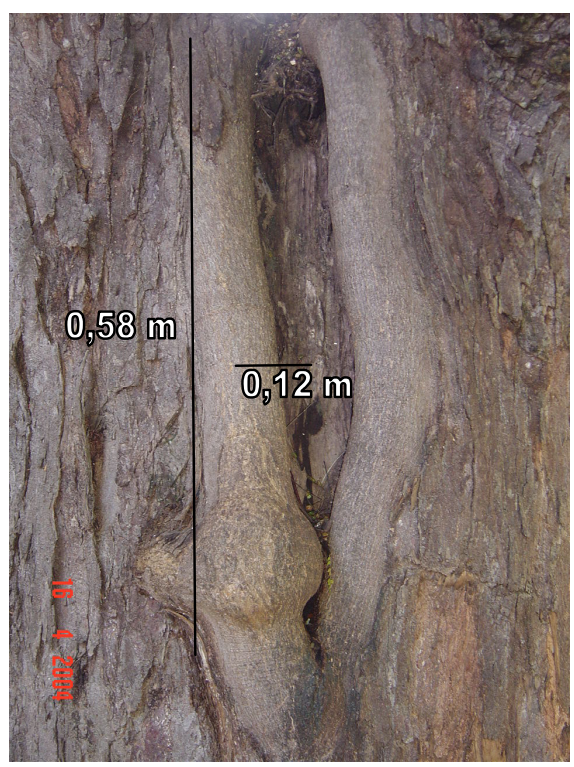

Figura 2 - Manifestação de cancro em Caesalpinea peltophoroides (sibipiruna), com grau de severidade 2 - severidade baixa.

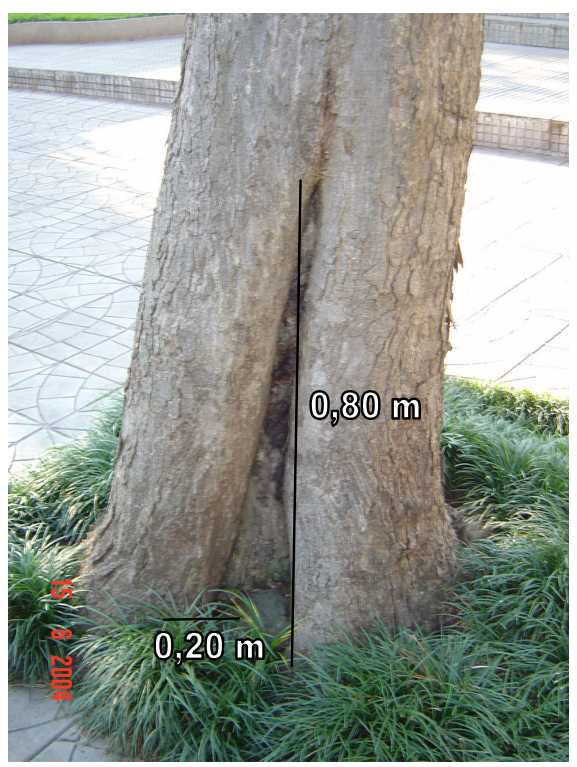

Figura 3 - Manifestação de cancro em Caesalpinea peltophoroides (sibipiruna), com grau de severidade 3 - severidade média. 


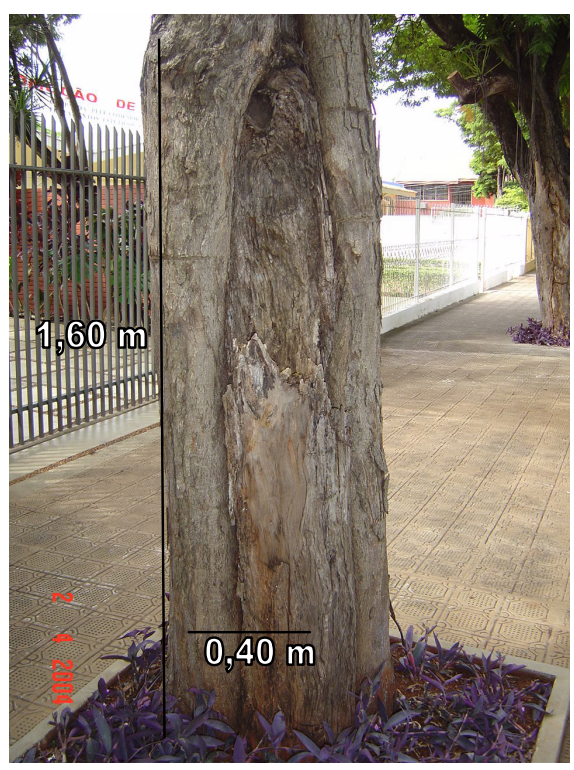

Figura 4 - Manifestação de cancro em Caesalpinea peltophoroides (sibipiruna), com grau de severidade 4 - severidade alta.

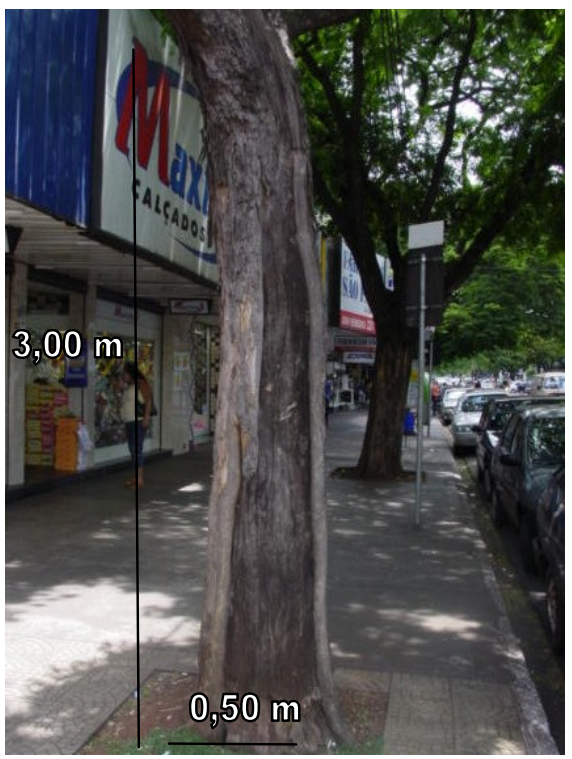

Figura 5 - Manifestação de cancro em Caesalpinea peltophoroides (sibipiruna), com grau de severidade 5 - severidade muito alta.

\section{RESULTADOS E DISCUSSÃO}

Como resultado da primeira etapa do trabalho, censo total da arborização nas duas áreas, foram identificadas 4.446 árvores distribuídas em 34 espécies, sendo 1.727 na Zona 1 e 2.719 na Zona 2 (Tabela 1). 
Tabela 1 - Levantamento quantitativo das espécies arbóreas de maior ocorrência nas zonas 1 e 2 - número de árvores por espécie plantada $\left(n .^{\circ}\right)$ e frequência real de plantio (f.r. \%)

\begin{tabular}{l|l|c|c|c|c}
\hline \multirow{2}{*}{ NOME CIENTíFICO } & \multirow{2}{*}{$\begin{array}{c}\text { NOME } \\
\text { COMUM }\end{array}$} & \multicolumn{2}{c|}{ ZONA 1 } & \multicolumn{2}{c}{ ZONA 2 } \\
\cline { 3 - 6 } & N.o & $\begin{array}{c}\text { F.R. } \\
(\%)\end{array}$ & N.o & $\begin{array}{c}\text { F.R. } \\
\text { (\%) }\end{array}$ \\
\hline Caesalpinea peltophoroides & Sibipiruna & 758 & 43,89 & 1641 & 60,35 \\
Tipuana tipu & Tipuana & 348 & 20,15 & 193 & 7,10 \\
Holocalyx balansae & Alecrim & 161 & 9,32 & 115 & 4,23 \\
Jacarandá mimosaefolia & Jacarandá & 108 & 6,25 & 110 & 4,05 \\
Delonix regia & Flamboyant & 96 & 5,56 & 60 & 2,21 \\
Tabebuia avellanedae & Ipê-roxo & 59 & 3,42 & 194 & 7,13 \\
Grevillea robusta & Grevílea & 54 & 3,12 & - & - \\
Tabebuia chrysotricha & Ipê-amarelo & 53 & 3,07 & 49 & 1,80 \\
Caesalpinea leyostachia & Pau-ferro & 21 & 1,22 & - & - \\
Fícus benjamina & Fícus & 13 & 0,75 & 39 & 1,43 \\
Tabebuia sp. & Ipê-branco & - & - & 73 & 2,68 \\
Licania tomentosa & Oiti & - & - & 55 & 2,02 \\
Caesalpinea echinata & Pau-Brasil & 10 & 0,58 & 42 & 1,54 \\
\hline
\end{tabular}

Com relação à presença do cancro nas duas áreas estudadas, os dados podem ser observados na Tabela 2. Esses dados mostram que existe uma diferença na ocorrência do cancro entre a Zona 1, que é de 17,31 \%, em relação a Zona 2, que tem 11,88 \% de ocorrência. A princípio tem-se que esta diferença possa ser creditada ao fato da Zona 1 estar localizada na região central da cidade onde, conforme já abordado anteriormente, apresenta características bastante particulares quando comparadas àquelas da Zona 2. No entanto, por se tratar do primeiro trabalho dessa natureza na cidade de Maringá, não se pode concluir em definitivo que esse seja o fator causal de uma maior incidência de cancro na área central. Consta-se ainda nos indivíduos arbóreos da Zona 1 uma maior ação vandálica (ferimentos, galhos quebrados, fixação de cartazes, utilização dos troncos como local para "estacionar" bicicletas e motos), predispondo-os a uma maior manifestação do cancro. Estes tipos de danos causados à arborização, além de deixá-las mais vulneráveis com o estresse causado a planta, também se tornam porta de entrada para patógenos, entre eles o(s) agente(s) causal(is) do cancro.

Tabela 2 - Ocorrência do cancro na área de estudo

\begin{tabular}{c|c|c|c}
\hline LOCAL & $\begin{array}{c}\text { № TOTAL DE } \\
\text { ÁRVORES }\end{array}$ & $\begin{array}{c}\text { № DE ÁRVORES } \\
\text { COM CANCRO }\end{array}$ & $\begin{array}{c}\text { ÁRVORES COM } \\
\text { CANCRO (\%) }\end{array}$ \\
\hline Zona 1 & 1.727 & 299 & 17,31 \\
Zona 2 & 2.719 & 323 & 11,88 \\
Zona 1 + Zona 2 & 4.446 & 622 & 13,99 \\
\hline
\end{tabular}


Com relação à severidade do cancro encontrada nas árvores estudadas tem-se que a grande maioria, cerca de $90 \%$, tem grau de severidade 1, 2 e 3 . Tomando-se, por exemplo, uma árvore com grau de severidade 3, com até $25 \%$ do tronco com sintoma, é uma árvore com $1 / 4$ da área do tronco lesionada. A severidade 2 é a de maior ocorrência, $37,45 \%$ das árvores com cancro. Seguida da severidade 3 , com $31,51 \%$ das árvores e severidade 1 com 24,92\%. A severidade 4 vem em penúltimo lugar com 4,01\% seguida da severidade 5 com 2,09\% e a menor ocorrência.

A composição da arborização encontrada em toda área de abrangência do estudo está representada por 34 espécies, sendo que a ocorrência do cancro foi verificada em 14 destas. A distribuição entre ocorrência e espécie pode ser verificada na Tabela 3.

Tabela 3 - Ocorrência do cancro (\%) e grau de severidade nas duas áreas de estudo - zona 1 e zona 2

\begin{tabular}{|c|c|c|c|c|c|}
\hline \multirow[t]{2}{*}{ Nome científico } & \multirow{2}{*}{$\begin{array}{l}\text { Nome } \\
\text { comum }\end{array}$} & \multicolumn{2}{|c|}{ Ocorrência (\%) } & \multicolumn{2}{|c|}{$\begin{array}{c}\text { Grau de } \\
\text { Severidade }\end{array}$} \\
\hline & & Zona 1 & Zona 2 & Zona 1 & Zona 2 \\
\hline Caesalpinea leyostachia & Pau-ferro & 28,57 & - & 3 & - \\
\hline Grevillea robusta & Grevílea & 27,77 & _ & 3 & _- \\
\hline Caesalpinea peltophoroides & Sibipiruna & 23,35 & 16,20 & 3 & 3 \\
\hline Holocalyx balansae & Alecrim & 20,49 & 7,82 & 2 & 2 \\
\hline Fícus benjamina & Fícus & 15,38 & 2,56 & 3 & 3 \\
\hline Jacarandá mimosaefolia & Jacarandá & 14,81 & 13,63 & 2 & 3 \\
\hline Tipuana tipu & Tipuana & 11,20 & 9,32 & 2 & 2 \\
\hline Schinus terebinthifolius & Aroeira & 10,00 & - & 1 & - \\
\hline Delonix regia & Flamboyant & 6,25 & 8,33 & 2 & 3 \\
\hline Tabebuia chrysotricha & Ipê-amarelo & 5,66 & - & 3 & - \\
\hline Tabebuia avellanedae & Ipê-roxo & 1,69 & 2,57 & 3 & 2 \\
\hline Chorisia speciosa & Paineira & - & $100,00^{5}$ & - & 3 \\
\hline Spathodea campanulata & Espatódea & - & 5,12 & - & 3 \\
\hline Licania tomentosa & Oiti & - & 1,81 & - & 3 \\
\hline
\end{tabular}

Com relação à ocorrência do cancro dentro das espécies tem-se o pau-ferro e a grevílea com as maiores ocorrências verificadas: $28,57 \%$ e $27,77 \%$, respectivamente. No

\footnotetext{
${ }^{5}$ A ocorrência de 100 \% na espécie Paineira (Chorisia speciosa) não é significativa, pois é relatada a ocorrência de somente um indivíduo.
} 
entanto, com relação a estas duas espécies os dados não são significativos, pois são espécies encontradas com pouca freqüência na área de estudo ${ }^{6}$. 0 dado mais preocupante vem com relação à sibipiruna que representa $43,89 \%$ das árvores presentes na Zona 1 e $60,35 \%$ da Zona 2, aparecendo com alto índice de ocorrência da doença: 23,35\% na Zona 1 e $16,20 \%$ na Zona 2. A espécie em questão responde por mais de $50 \%$ da arborização de acompanhamento viário da área de estudo. No caso da sibipiruna, outro dado preocupante é a severidade da doença na espécie, onde nas duas áreas é encontrada média de severidade 3. Portanto, a espécie de maior ocorrência além de ter alta porcentagem de manifestação de cancro ainda tem severidade média 3.

$\mathrm{Na}$ interação cancro, espécie, altura média das árvores e porcentagem de ocorrência, nota-se que a maioria das espécies tem altura média maior na Zona 1, onde também a ocorrência do cancro é maior. Portanto, existe uma interação entre altura média da arborização e porcentagem de ocorrência da doença, associado ao estresse a que estão submetidas essas árvores. O fato de a altura média ser maior na Zona 1 talvez deva-se as edificações, onde as árvores tendes a um fototropismo positivo, ou seja, busca a luz por entre as edificações ou por cima delas, já que a área central de Maringá apresenta um elevado grau de sombreamento. Talvez seja o único fato que justifique o dado, já que a arborização das duas zonas tem, praticamente, a mesma idade.

A manifestação do cancro dá-se de forma mais acentuada em árvores de diâmetro maior na Zona 1, se comparado com aquelas da Zona 2. Biondi e Reissmann (1997) avaliando o vigor das árvores urbanas, e também fazendo um comparativo entre áreas poluídas e não poluídas, relatam que árvores numa condição mais hostil apresentem maior tamanho de copa. Os dados obtidos no trabalho citado revelam similaridade com a situação exposta aqui, pois a Zona 1, área onde a média do diâmetro de copa é maior, também é uma área de condições mais hostis, ou seja as condições para o desenvolvimento da arborização são mais adversas.

Relacionando-se a área livre média das espécies com cancro e porcentagem de ocorrência nas Zonas 1 e 2 tem-se que a área livre média da Zona 2, na maioria dos indivíduos arbóreos, é maior que a área livre média da Zona 1. Este fato contribui significativamente para a menor ocorrência do cancro na Zona 2. Segundo Milano (1988) apud Biondi (1985) a área livre está relacionada aos aspectos fisiológicos de aeração do solo e disponibilidade de nutrientes para as plantas. Ainda de acordo com Milano (1988) a área livre é um fator de significativa importância ao adequado desenvolvimento e condição fitossanitária da arborização. Uma árvore com área livre maior está submetida a uma menor condição de estresse, tendo em vista maior disponibilidade de água e nutrientes e tem seu

\footnotetext{
${ }^{6} \mathrm{Na}$ Zona 1 a grevílea responde por 3,12\% do total levantado, enquanto o pau-ferro com 1,22\%; por sua vez na Zona 2 não há presença de grevíleas, e o pau-ferro representa $0,11 \%$ do total da arborização.
} 
crescimento livre de impedimentos físicos. Estes fatores contribuem para uma melhor condição de defesa da planta contra patógenos, pois uma planta saudável está menos susceptível ao ataque.

Com relação ao DAP médio das espécies nota-se uma maior média na Zona 2, o que representa um melhor desenvolvimento das árvores nesta área. Relacionando média de DAP com \% de ocorrência do cancro tem-se que onde o DAP é maior, Zona 2, existe uma menor ocorrência de cancro. Estes resultados indicam que em locais residenciais existe um melhor desenvolvimento de árvores, tornando-as mais resistentes ao ataque de patógenos. Biondi e Reissmann (1997) avaliando vigor de árvores urbanas constataram que as menores médias de DAP foram para árvore em local poluído. A citação revela fato semelhante ao encontrado, pois a média de DAP encontrada na Zona 1, área mais central da cidade, foi menor que a média encontrada na Zona 2.

$\mathrm{Na}$ interação condução de poda e ocorrência de cancro nota-se uma significativa maior ocorrência da doença em árvores localizadas na Zona 1; tal fato que já era esperado devido a competição por espaço com fiação e edifícios. A poda drástica e a ocorrência de cancro têm estreita relação, já que a poda produz ferimentos dos mais diversos na árvore, tornando-se porta de entrada para patógenos, o que justifica uma menor porcentagem de ocorrência de cancro na Zona 2, local onde a poda drástica ocorre em menor porcentagem. Existe ainda uma relação entre poda e DAP, onde de acordo com Balensiefer (1983) a poda severa diminui a intensidade de crescimento em DAP, fato que talvez justifique a menor média de DAP encontrada na Zona 1, local onde a porcentagem de poda severa é maior.

Com relação a sistema radicular e ocorrência de cancro tem-se que a maioria das árvores possui sistema radicular sem afloramento na área livre;.no que diz respeito à ocorrência de cancro não foi encontrada nenhuma interação entre os dados.

\section{CONCLUSÕES}

Constata-se que as árvores da Zona 1 vivem em uma condição mais hostil o que, certamente, as predispõe a uma maior incidência de cancro. Nesse contexto é possível apresentar algumas conclusões, conforme segue.

$\checkmark$ Dentre as árvores avaliadas há a manifestação do cancro em $17,31 \%$ das existentes na Zona 1 e em $11,88 \%$ da Zona 2. Portanto, é notável a maior ocorrência do cancro na Zona 1.

$\checkmark$ Cerca de $70 \%$ das árvores com sintomas da doença apresentam grau de severidade entre baixa e média (grau de severidade 2 e 3 ). 
$\checkmark$ As espécies pau-ferro (Caesalpinea leyostachia), grevílea (Grevillea robusta) e sibipiruna (Caesalpinea peltophoroides) têm as maiores ocorrências de cancro verificada, $28,57 \%, 27,77 \%$ e $23,35 \%$, respectivamente.

$\checkmark$ A maioria das espécies tem altura média maior na Zona 1, onde estão as maiores porcentagem de ocorrência de cancro, portanto existe uma correlação entre altura média e ocorrência de cancro. O mesmo fato ocorre com relação ao diâmetro de copa naquela Zona onde, maior a média, maior a ocorrência do cancro.

$\checkmark$ A poda drástica é encontrada com maior freqüência na Zona 1, onde também é maior a ocorrência de cancro.

$\checkmark$ Na maioria das espécies a porcentagem de ocorrência de cancro é maior na Zona 1 do que na Zona 2.

\section{REFERÊNCIAS BIBLIOGRÁFICAS}

AMORIM, L. Avaliação de doenças. In: BERGAMIN FILHO, Armando; KIMATI, Hiroshi; AMORIM, Lílian. (Ed). Manual de Fitopatologia, vol. 1: Princípios e conceitos. 3. ed. São Paulo: Agronômica Ceres. 1995. 919 p.

BALENSIEFER, M. Poda em arborização urbana. Instituto de Terras e Cartografia. Departamento de Recursos Naturais Renováveis. Curitiba. 1983.

BERNATZKY, A. Tree ecology and preservation. 2. ed. Amsterdan: Elsevier, 1980.

BIONDI, D; REISSMANN, C. B. Avaliação do vigor das árvores urbanas através de parâmetros quantitativos. Scientia forestalis. N.52, p. 17-28, dez. 1997. Disponível em:<http://www.ufra.edu.br/ltpf/bibliografia/Avaliacao\%20do\%20vigor\%20das\%20arvores\%2 Ourbanas.pdf>. Acesso em: 31 mai. 2004.

JÚNIOR, C. A. P. Obtenção de resistência como controle de ferrugem e cancro do eucalipto. Universidade Federal de Viçosa. Disponível em: <http://www.ufv.br/dbg/bioano02/a2001a21.htm>. Acesso em: 12 mai. 2004.

MENEGHEL, T. Alerta: verde de Maringá corre perigo. Folha do Paraná. 18 de fev. de 2001. Disponível em: <http://www.ambicenter.com.br/art01021901.htm>. Acesso em: 15 mai. 2004. 